\title{
An In Vitro Evaluation of Antibacterial and Smear Layer Removal Efficacy of Silver Nanoparticles as Final Irrigant against Enterococcus Faecalis
}

\author{
Reshma Rajasekhar ${ }^{1}$, Baby James ${ }^{2}$, Aravindan Devadathan ${ }^{3}$, Sooraj Soman ${ }^{4}$, Varsha M Sebastian ${ }^{5}$, Midhula Sathyan ${ }^{6}$
}

\begin{abstract}
Aim and objective: The aim and objective of this study is to assess the antibacterial and smear layer removal efficacy of silver nanoparticles as final irrigant against Enterococcus faecalis (E. faecalis) using confocal laser scanning and scanning electron microscope, respectively.

Materials and methods: Forty single-rooted mandibular premolar teeth were instrumented till Protaper Gold F3 after decoronation. E. faecalis were inoculated in all samples and they were divided into five groups based on the irrigant used into group $A=$ silver nanoparticle (AgNp), group $B=A g N p+17 \%$ ethylenediamine tetraacetic acid (EDTA), group $C=5.25 \%$ sodium hypochlorite $(\mathrm{NaOCl}), \mathrm{group} D=\mathrm{NaOCl} 5.25 \%+17 \%$ EDTA, group $E=$ Distilled water. After irrigation roots were split longitudinally and assessed for confocal and SEM.

Results: Groups $C$ and D showed the greatest reduction in the percentage of live bacteria with no significant difference between them. Groups $A$ and $B$ has shown reduction in live bacterial percentage but not greater than groups $C$ and $D$. Group E showed the greatest percentage of live bacteria. In smear layer analysis, greatest amount of smear layer was found in groups $C$ and $E$ in the coronal, middle, and apical third with no significant difference between them. However, greater smear layer reduction was seen in groups B and D. Group A has shown reduction in smear layer score which is greater than group $\mathrm{C}$ with significant difference between them.

Conclusion: Irrigation with $\mathrm{NaOCl}$ (group C), $\mathrm{NaOCl}+17 \%$ EDTA (group D) showed greatest reduction in live bacteria followed by AgNp $+17 \%$ EDTA (Group B) and AgNp (group A) whereas greater smear layer removal is seen with irrigation with AgNp $+17 \%$ EDTA (group B) and NaOCI $+17 \%$ EDTA (group D) followed by AgNp (group A), $\mathrm{NaOCl}$ (group C).

Clinical significance: Based on the results from this study, AgNp irrigant has some antibacterial and smear layer removal capability. This study shows the possible potential of using nanoparticles as a single irrigant which can have dual action of antibacterial and smear layer removal efficacy. Keywords: Confocal laser scanning microscopy, Enterococcus faecalis, EDTA, Nanoparticles, Scanning electron microscopy, Sodium hypochlorite. World Journal of Dentistry (2022): 10.5005/jp-journals-10015-1913
\end{abstract}

\section{INTRODUCTION}

Root canal system is complex because of the presence of isthmuses, ramifications, fins, apical delta, lateral canals, dentinal tubules etc. These areas promote bacterial biofilm formation and affect the prognosis of endodontic treatment.

Bacteria in biofilm state shows distinct capacity to survive tough growth and environmental conditions. Thus, instrumentation coupled with an efficient antimicrobial irrigant is effective in achieving sufficient reduction in bacterial load. ${ }^{2,3}$

Persistent or secondary infection, is regarded as the major cause of endodontic treatment failure and are composed of one or few bacterial species especially Enterococcus faecalis (E. faecalis). ${ }^{4,5}$

Persistence of $E$ faecalis is mainly because it endures prolonged starvation period, it possess serine protease, gelatinase, and collagen binding protein, which helps it bind to dentin, exhibits widespread genetic polymorphisms, invade and live within dentinal tubules to a deep extent. ${ }^{6}$ It alters host response, supresses action of lymphocytes, possess lytic enzymes, cytolysin, aggregation substances, pheromones, lipoteichoic acid, utilizes serum as nutritional source, resist calcium hydroxide treatment, ${ }^{7}$ competes with other cells and forms biofilms, can enter viable but noncultivable state. ${ }^{8}$

Sodium hypochlorite $(\mathrm{NaOCl})$ is the most commonly recommended endodontic irrigant due to its effective antimicrobial \begin{tabular}{l}
\hline 1,5 Department of Conservative Dentistry and Endodontics, MES Dental \\
College, Perinthalmanna, Malappuram, Kerala, India \\
2,3 Department of Conservative Dentistry and Endodontics, Pushpagiri \\
Dental College, Thiruvalla, Kerala, India \\
${ }^{4}$ Department of Oral and Maxillofacial Surgery, MES Dental College, \\
Perinthalmanna, Malappuram, Kerala, India \\
${ }^{6}$ Consultant Endodontist, Manas-Krishnanivas, Varavila, Kollam, Kerala,
\end{tabular} ${ }^{6}$ Consulia

Corresponding Author: Reshma Rajasekhar, Department of Conservative Dentistry and Endodontics, MES Dental College, Perinthalmanna, Malappuram, Kerala, India, Phone: +91 8606008164 , e-mail: reshmarajasekhar@gmail.com

How to cite this article: Rajasekhar R, James B, Devadathan A, et al. An In Vitro Evaluation of Antibacterial and Smear Layer Removal Efficacy of Silver Nanoparticles as Final Irrigant against Enterococcus Faecalis. World J Dent 2022;13(2):148-154.

Source of support: Nil

Conflict of interest: None

activity but it does not remove the inorganic component of smear layer. ${ }^{9}$ Removal of inorganic component of smear layer occurs by application of $17 \%$ ethylenediamine tetraacetic acid (EDTA) for less than 1 minute. $^{5}$

(c) The Author(s). 2022 Open Access This article is distributed under the terms of the Creative Commons Attribution 4.0 International License (https://creativecommons. org/licenses/by-nc/4.0/), which permits unrestricted use, distribution, and non-commercial reproduction in any medium, provided you give appropriate credit to the original author(s) and the source, provide a link to the Creative Commons license, and indicate if changes were made. The Creative Commons Public Domain Dedication waiver (http://creativecommons.org/publicdomain/zero/1.0/) applies to the data made available in this article, unless otherwise stated. 
An alternative irrigant having optimum antimicrobial and smear layer removal property along with less side effects are an area of interest and nanoparticles has been under research for this purpose.

In dentistry, silver nanoparticles (AgNp) have been tested for its application as dental restorative material, endodontic retrofill material, dental implants, and caries inhibitory solution. Silver nanoparticles have high surface area to volume ratio, unique chemical and physical properties leading to increased reactivity compared to its bulk counterparts. They act on multiple target sites, interact with sulfhydryl groups of proteins and DNA, alter hydrogen bonding/respiratory chain, unwind DNA, interfere with cell wall synthesis/cell division, destabilize bacterial membrane, and contributes to leakage of cell constituents. ${ }^{10,11}$ Silver nanoparticle has been widely studied in endodontics because of its broad antimicrobial action even in multidrug resistant strains. ${ }^{12-14}$ Therefore its use as an endodontic irrigant is a promising area undergoing further researches.

The aim of this in vitro study is to assess the potential of silver nanoparticles as final irrigant against $E$. faecalis on extracted human teeth. Evaluation of the antibacterial efficacy were made by determining the percentage of live bacterial cells by using confocal laser scanning microscope (CLSM) and smear layer removal efficacy were determined by using scanning electron microscopic evaluation (SEM).

\section{Materials and Methods}

\section{Sample Preparation}

After getting approval from institutional ethical committee (IEC/J8/11/16). Forty single-rooted noncarious mandibular premolars without calcification, resorption or excessive root curvature that were extracted for orthodontic purpose from patients of age group 14-25 years were selected for the study. Buccolingual and mesiodistal radiographs of the teeth were taken to ensure single root canal. They were stored in $0.1 \%$ thymol for 24 hours and were washed with running water and air dried. Acrylic blocks were fabricated for each tooth to facilitate placement during irrigation.

Teeth were decoronated with the help of a diamond disk to obtain a uniform length of $15 \mathrm{~mm}$. Longitudinal grooves of $1 \mathrm{~mm}$ depth were made on buccal and lingual aspect of root. Patency of root canal was achieved with $10 \mathrm{~K}$-file and working length were determined by introducing $15 \mathrm{~K}$ stainless steel file until the tip was visible beyond the apical foramen and $1 \mathrm{~mm}$ deducted from this length. ProTaper gold rotary instruments were used till F3 along with $5 \mathrm{~mL}$ of $1 \% \mathrm{NaOCl}$ irrigation using a $30 \mathrm{G}$ side vented needle.

Teeth were placed in falcon tubes and autoclaved for 15 minutes at $15 \mathrm{lbs}$ pressure and $121^{\circ} \mathrm{C}$. Each tooth received $1 \mathrm{~mL}$ of brain heart infusion brain heart infusion (BHI) broth and incubated for 24 hours at $37^{\circ} \mathrm{C}$ in incubator to determine the efficiency of sterilization.

\section{Silver Nanoparticle Solution Preparation}

An amount of $0.1 \mathrm{gm}$ of silver nanoparticles of $10 \mathrm{~nm}$ size range (Sigma Aldrich, USA) were diluted with $100 \mathrm{~mL}$ of distilled water in a falcon tube and placed in a sonicator to prepare $0.1 \%$ silver nanoparticle solution.

\section{Preparation of E. faecalis Culture}

E. faecalis (ATCC 29212) were plated in BHI broth supplemented with $1.5 \%(\mathrm{w} / \mathrm{v})$ agar and incubated at $37^{\circ} \mathrm{C}$ for 24 hours. Single colony of $E$. faecalis from $\mathrm{BHI}$ agar plate was picked and suspended in sterile $\mathrm{BHI}$ broth at $37^{\circ} \mathrm{C}$. Then the broth was standardized by means of spectrophotometer. The culture was set to 0.1 optical density (OD) at $595 \mathrm{~nm}$.

\section{Inoculation of $E$. faecalis Culture into the Samples}

An amount of $100 \mu \mathrm{L} E$. faecalis culture was inoculated into the prepared root canal with an insulin syringe of $30 \mathrm{G}$ needle. After inoculation, each specimen was submerged in $\mathrm{BH}$ broth filled tubes and incubated anaerobically at $37^{\circ} \mathrm{C}$ for 3 days and refreshed with fresh broth every 8 hours. In three randomly picked samples bacterial viability were checked by streaking an inoculating loop placed in the broth into $\mathrm{BH}$ agar and incubating it overnight at $37^{\circ} \mathrm{C}$ to determine the growth of $E$. faecalis.

\section{Irrigation of Samples}

After incubation, the medium was aspirated from the tubes and the canals were dried with paper points and were placed in acrylic blocks to facilitate irrigation.

The teeth were randomly divided into five groups with eight samples each based on the type of irrigant used and were irrigated for 5 minutes with $5 \mathrm{~mL}$ of irrigant, using 30-gauge side vented irrigation needle placed at $13 \mathrm{~mm}$ from apex. Sample size were calculated using the formula: $\mathrm{N}=\left(Z^{\alpha}+Z^{\beta}\right)^{2} \times 2 \sigma^{2} / d^{2}$

- Group A = Silver nanoparticle (AgNp)

- Group B = Silver nanoparticle (AgNp) + 17\% EDTA

- Group C = Sodium hypochlorite $(\mathrm{NaOCl}) 5.25 \%$

- Group D = Sodium hypochlorite (NaOCl) 5.25\% + 17\% EDTA

- Group E = Distilled water (control).

After completion of irrigation, roots were split longitudinally with a sterilized chisel and mallet.

One half of the root of all samples from each group were used for confocal laser scanning microscopic analysis whereas the other halves were used for SEM at three areas in the root such as coronal, middle, and apical third.

\section{Confocal Laser Scanning Microscopic Analysis}

Samples were stained with fluorescent LIVE/DEAD BacLight Bacterial Viability stain (Molecular Probes, Eugene) containing SYTO9 and propidium iodide (PI). One $\mu \mathrm{L}$ of SYTO 9 and $1 \mu \mathrm{L}$ of PI was added to $1 \mathrm{~mL}$ sterile Milli Q. This dye mixture was used to stain the bacterial cells and incubated for 5-7 minutes following which the samples were rinsed with phosphate buffered saline and proceeded for confocal imaging.

The excitation/emission wavelengths were $480 / 500 \mathrm{~nm}$ for SYTO 9 and 490/635 nm for PI. Fluorescence was viewed by using confocal laser scanning microscope (Nikon A1R). The mounted specimens were observed by using a 20x lens. Confocal images were acquired by the software (NB2, Nikon) at a resolution of $512 \mathrm{x}$ 512 pixels. Ten $\mu \mathrm{m}$-deep scans $(0.5 \mathrm{~mm}$ step size, 20 slices/scan) were obtained from five randomly selected areas of each dentin specimen. Figure 1 represents the confocal images obtained for all groups. Red color represents dead bacteria whereas green color shows live bacteria. The percentage of live bacteria were calculated using Fiji software (Fiji v.1.47n; Madison, WI).

\section{Scanning Electron Microscopic Analysis}

For SEM samples were fixed in a $2 \%$ glutaraldehyde solution for 4 hours at $4^{\circ} \mathrm{C}$, then washed in deionized water. Dehydration achieved with graded series of ethanol $(35,50,70,90$, and $100 \%$ for 15 minutes/each) and critical point drying were performed. 


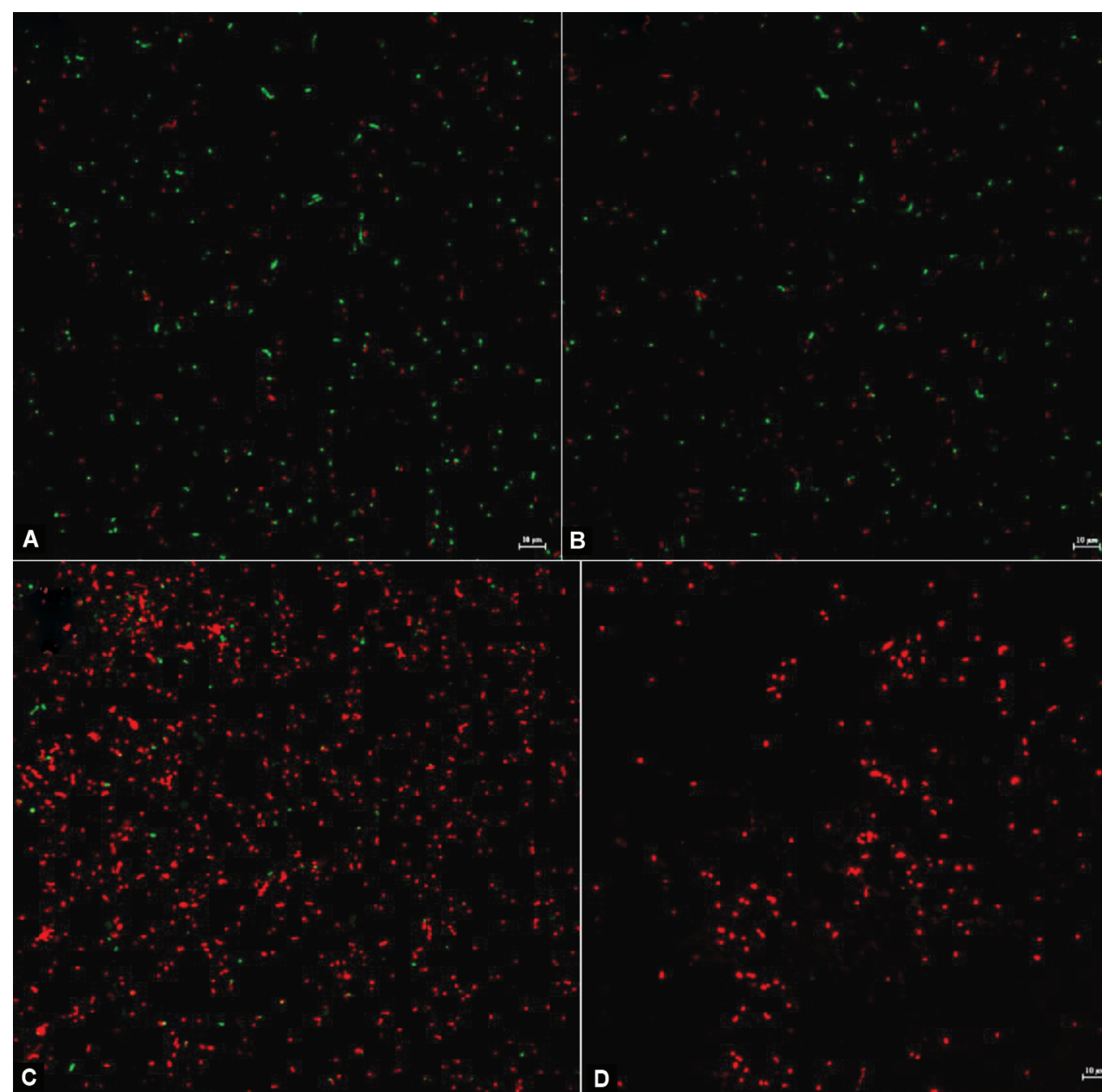

Figs 1A to D: Confocal laser scanning microscopic image of (A) Group A (AgNp); (B) Group B (AgNp+17\% EDTA); (C) Group C (NaOCl); (D) Group $\mathrm{D}(\mathrm{NaOCl}+17 \% \mathrm{EDTA})$ at $20 \times$ magnification

Samples were then sputter coated with $3-6 \mathrm{~nm}$ of gold, $10 \mathrm{~mA}$ for 90 seconds. Then they were observed under scanning electron microscope (Hitachi S2400) at a magnification of 1000x at coronal, middle, apical third for smear layer analysis as shown in Figure 2.

The images were scored according to the criteria given by Torabinejad et al. ${ }^{15}$

- Score 1 = no smear layer

- Score 2 = moderate smear layer

- Score 3 = heavy smear layer

Statistical analysis for groups assessing percentage of live bacteria and smear layer scores were done using Tukey Honestly significant difference (HSD) test. A $p$ value of $<0.05$ was considered as statistically significant. Statistical assessment was done using software SPSS version 19.0 (SPSS Inc, Chicago, IL, USA).

\section{Results}

Data for the degree of percentage of live bacteria were analyzed and presented as mean and standard deviation for different groups in Table 1 and Figure 3 shows the graphical representation of mean value of percentage of live bacteria. Result shows that lowest percentage of live bacteria seen in group $C$ and group $D$ with no significant difference between them, followed by group $A$ and group $B$ with significant difference among each other. Group E has the highest percentage of live bacteria with significant difference with rest of the groups.

Data for the smear layer analysis were analyzed and presented as mean and standard deviation for different groups in Table 2. Figure 4 shows the graphical representation of mean value of smear layer scores. Result shows that group E has greatest score of smear layer in coronal, middle, and apical third compared to all other groups followed by group C. Group A has higher score compared to group $B$ and group $D$ but the results are not statistically significant. group $B$ and group D showed the least smear layer score in the coronal, middle, and apical third with no statistically significant difference between them.

Based on the result, $\mathrm{NaOCl}$ groups (groups $\mathrm{C}$ and $\mathrm{D}$ ) has shown the greatest reduction in bacteria followed by AgNp irrigant used along with 17\% EDTA (group B) and when used alone (group A). Greater smear layer removal was seen when $\mathrm{NaOCl}$ and $\mathrm{AgNp}$ irrigant were used along with 17\% EDTA (groups B and D) followed by AgNp irrigant when used alone (group A).

\section{Discussion}

Achieving complete disinfection of the root canal system has been a major challenge faced by clinicians. It is mainly because of the biofilm mode of infection, complex root canal anatomy, inability of commonly used irrigants, and medicaments to eradicate 

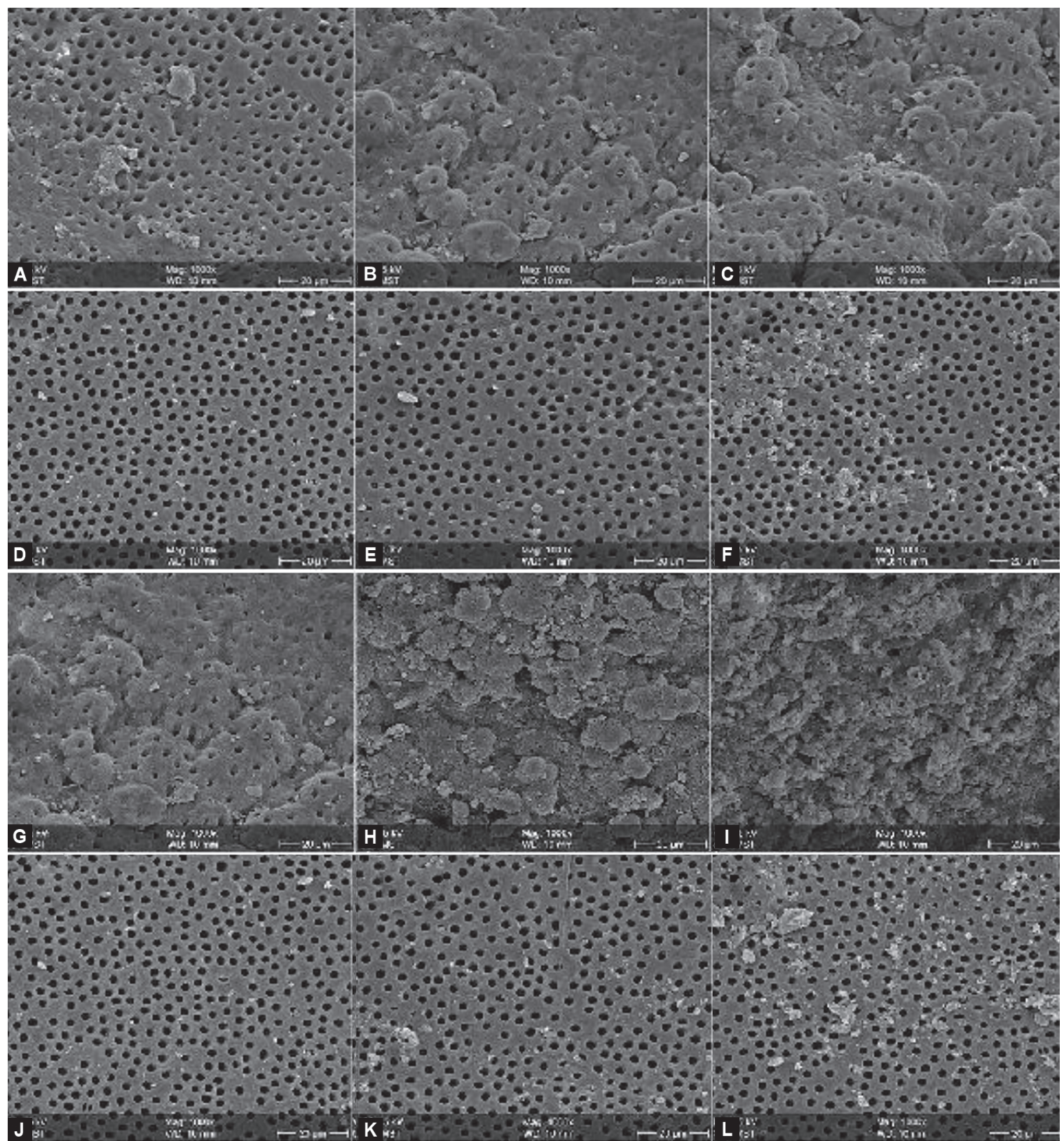

Figs $2 A$ to L: Scanning electron microscopic images (1000x) of Group A: (AgNp) showing coronal (A), middle (B), and apical third (C), Group B: coronal (D), middle (E), apical (F), Group C (NaOCl): coronal (G), middle (H), apical (I), Group D (NaOCl + EDTA): coronal (J), middle (K), apical (L)

Table 1: Mean and standard deviation of percentage of live bacteria

\begin{tabular}{lll}
\hline Irrigants & Mean & Std. deviation \\
\hline Group A (AgNP) & 41.30 & 6.55968 \\
Group B (AgNP+17\% EDTA) & 33.6650 & 5.01254 \\
Group C (NaOCl) & 23.4350 & 7.39419 \\
Group D (NaOCl+ 17\% EDTA) & 22.6475 & 10.52823 \\
Group E (Control) & 92.0675 & 2.48891 \\
\hline
\end{tabular}

resistant microorganisms. Studies have found that $E$. faecalis is one of the commonly recovered microorganisms which has been persistently found in failed endodontically treated cases with a prevalence range from 24 to $77 \% .^{16,17}$

It has been pointed out that apical periodontitis is a biofilm related disease. ${ }^{18}$ It is a basic survival strategy employed by microorganisms in response to starvation. Bacteria within biofilm exhibit altered properties compared to their planktonic counterparts. ${ }^{19}$

Various modalities have been proposed to eradicate the biofilm such as proteolytic agents like $\mathrm{NaOCl}$, chlorhexidine, EDTA, Mixture of Tetracycline isomer,Acid,Detergent (MTAD), phytotherapeutic agents, nanoparticles like chitosan, functionalized nanoparticles, enzymatic agents, etc. Among them the most widely used and considered as gold standard among clinicians is $\mathrm{NaOCl}$ which is used in the concentration ranging from 0.5 to $6 \% .{ }^{20}$ Its use in endodontics is indispensable and an effective alternative has not been achieved so far.

Efficacy of $\mathrm{NaOCl}$ against $E$. faecalis has been studied profoundly. According to Gomes et al., they evaluated the effect of various concentrations of $\mathrm{NaOCl}$ against $E$. faecalis. E. faecalis 
Antibacterial and Smear Layer Removal Efficacy of Silver Nanoparticle Irrigant

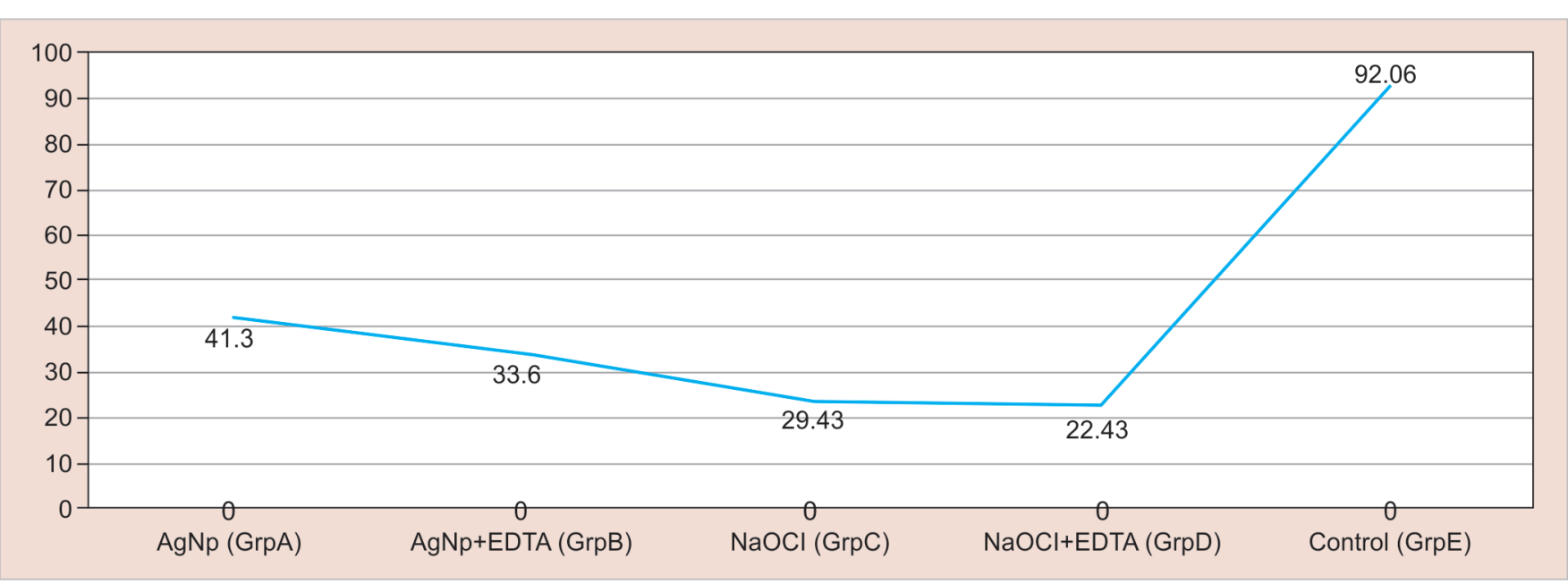

Fig. 3: Graph showing mean value of percentage of live bacteria

Table 2: Mean and standard deviation of smear layer scores

\begin{tabular}{lcccccc}
\hline & \multicolumn{3}{c}{ Coronal } & \multicolumn{2}{c}{ Middle } & Apical \\
\cline { 2 - 7 } Groups & Mean & $\begin{array}{c}\text { Std. } \\
\text { deviation }\end{array}$ & Mean & $\begin{array}{c}\text { Std. } \\
\text { deviation }\end{array}$ & Mean & $\begin{array}{c}\text { Std. } \\
\text { deviation }\end{array}$ \\
\hline Group A (AgNp) & 1.33 & 0.577 & 1.67 & 0.577 & 2.00 & 0.000 \\
Group B (AgNp+EDTA) & 1 & 0.000 & 1 & 0.000 & 1.67 & 0.577 \\
Group C & 2.67 & 0.577 & 2.33 & 0.577 & 3.00 & 0.000 \\
(NaOCl) & 1 & 0.000 & 1 & 0.000 & 1.33 & 0.577 \\
Group D (NaOCl+EDTA) & 3 & 0.000 & 3 & 0.000 & 3 & 0.000 \\
Group E (Control) & & & & & \\
\hline
\end{tabular}

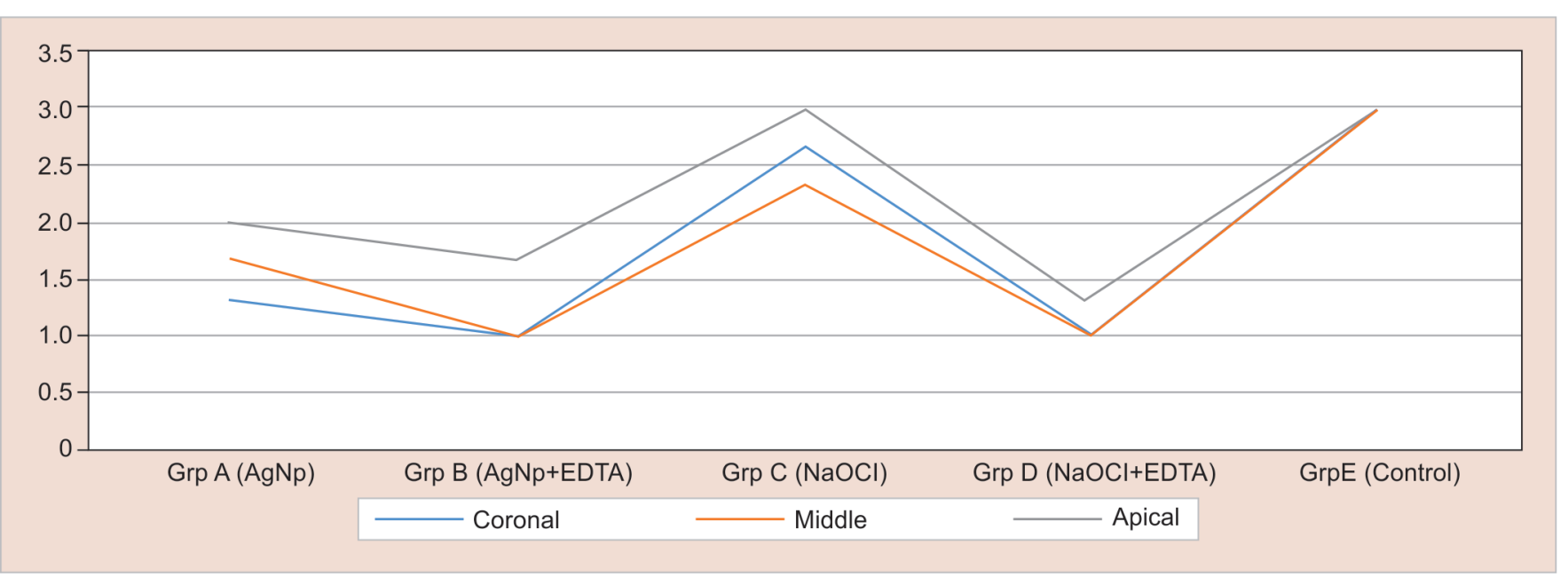

Fig. 4: Graph showing mean value of smear layer scores

were killed within 30 seconds by the $5.25 \%$ solution, while 10 and 30 minutes was required for killing all bacteria by 2.5 and $0.5 \%$ solutions, respectively. ${ }^{21}$

However, there are conflicting studies regarding the antibacterial effect of $\mathrm{NaOCl}$. Haapasalo et al. showed that the presence of dentin caused marked delays in the killing of E. faecalis by $1 \%$ $\mathrm{NaOCl}^{22}$ It has been shown that in in vivo conditions the presence of dentin constituents, tissue remnants, serum products in root canal could neutralize the antibacterial efficacy of sodium hypochlorite. ${ }^{23,24}$ Regarding the biofilm removal capacity, Rosen et al. reported that $\mathrm{NaOCl}$ induces a viable but nonculturable state of bacteria in biofilms and this could contribute to bacterial persistence. $^{25}$

In order to obtain complete removal of smear layer, sodium hypochlorite followed by $17 \%$ EDTA has been used. Both the irrigants are used indispensably during endodontic procedure. Recently, many irrigants has been introduced in the field of endodontics which claims to possess better antibacterial action but there is no satisfactory irrigant in market that can perform simultaneous antibacterial and smear layer removal capacity.

Recently, the research has shifted to understanding the benefits of nanoparticles in endodontics. Among the nanoparticles 
silver nanoparticles are being studied and has found to possess simultaneous antibacterial and smear layer removal efficacy. The mechanism of action of silver nanoparticles is mainly due to controlled release of silver ions in aqueous microenvironment. Owing to their large surface area and high reactivity compared to their bulk counterparts, silver nanoparticles exhibit remarkable physical, chemical, and biological properties. ${ }^{26}$ Studies show that silver nanoparticles with a size range of 10 to $100 \mathrm{~nm}$ showed good bactericidal potential against both Gram-positive and Gram-negative bacteria. ${ }^{27,28}$ The antibacterial action of silver nanoparticles is still not fully known. The three most common mechanisms of antibacterial activity described are: (1) uptake of free silver ions followed by disruption of adenosine triphosphate production and DNA replication, (2) silver nanoparticle and silver ion generation of reactive oxygen species, and (3) direct damage to cell membranes. ${ }^{29,30}$

In the present study, we are evaluating the antibacterial as well as smear layer removal efficacy of $0.1 \%$ silver nanoparticles as final irrigant against $E$. faecalis biofilm. According to the results obtained in this study, Group A (AgNp) has shown a mean 41.3\% live bacteria and shows acceptable bactericidal properties. According to Zhuang et al., they studied $0.1 \%$ silver nanoparticles irrigant against $E$. faecalis and has shown strong bactericidal effect against its biofilm formed on dentin after 24 hours of exposure. ${ }^{31}$ Gonzalez luna et al. evaluated the antibacterial efficacy of silver nanoparticle irrigant against $E$. faecalis and found to possess acceptable antibacterial efficacy comparable to $2.25 \%$ sodium hypochlorite. ${ }^{32}$

According to Xiomei et al., they assessed the efficacy of silver nanoparticles on the bacterial growth and changes in the transcriptome of $E$. faecalis using RNA sequencing technology. Results showed that silver nanoparticles significantly inhibited growth of $E$. faecalis by prolonging the lag phase in a dose dependent manner showing the bactericidal potential of silver nanoparticle against $E$. faecalis. ${ }^{33}$

Group B (AgNP+EDTA) has shown mean 33.6\% live bacteria remaining which is less than Group $A$. This is in agreement with the study done by Andrade et al., where they evaluated the chelating and antimicrobial capacity of a novel modification of $17 \%$ EDTA with silver nanoparticles against Candida albicans and Staphylococcus aureus in planktonic and biofilm cells. They found that the $17 \%$ EDTA-silver nanoparticle solution proved to be an effective antimicrobial agent, and has a similar chelating capacity to $17 \%$ EDTA. ${ }^{34}$ But according to Gonzalez luna et al., they found that the antibacterial effect of silver nanoparticle followed by $17 \%$ EDTA is lower as compared to silver nanoparticle irrigant when used alone and they explained that it could be due to the chelating property of EDTA and these results are in contrast with our study. ${ }^{32}$

Group C ( $\mathrm{NaOCl}$ ) has shown a mean $23.43 \%$ live bacteria. The result obtained in this study has shown the greatest reduction in percentage of live bacteria, which is followed by silver nanoparticle irrigant (Group A). According to Rodrigues et al., 2.5\% sodium hypochlorite had the greatest antimicrobial and biofilm dissolution ability compared to $94 \mathrm{ppm}$ silver nanoparticle solution, $2 \%$ chlorhexidine solution against $E$. faecalis biofilm on bovine dentine blocks. In this study antimicrobial effectiveness of irrigants against 3 days old $E$. faecalis biofilm is evaluated and $5.25 \%$ sodium hypochorite possess the greatest antibacterial efficacy followed by silver nanoparticle irrigant. ${ }^{35}$ Balto et al., evaluated the antibiofilm efficacy of calcium hydroxide mixed with $0.02 \%$ silver nanoparticles in comparison with $1 \mathrm{mg} / \mathrm{mL}$ triple antibiotic paste (TAP), calcium hydroxide, and $0.02 \%$ AgNps against 3 week old E. faecalis biofilm using confocal laser scanning microscopy. They found that the mixture of $\mathrm{Ca}(\mathrm{OH})_{2}+$ AgNps showed a high antibiofilm effect and was not significantly different from $1 \mathrm{mg} / \mathrm{mL}$ TAP. ${ }^{36}$ According to study by Wu et al., they showed that silver nanoparticle placed as medicament were more effective than irrigant against 4 weeks old E. faecalis biofilm. ${ }^{37}$ This is in contrast with our study this might be because $E$. faecalis biofilm has attained more maturation in 4 weeks and possess greater resistance to antimicrobials than 3 days old biofilm. Therefore, sufficient duration of contact was required to enable antimicrobial activity. This is in accordance with studies showing that rate of bacterial killing by nanoparticles depended on its concentration and duration of action. ${ }^{31,38,39}$

Scanning electron microscopic images obtained has shown that Group A (AgNp) has better smear layer removal efficacy compared to sodium hypochlorite and is in agreement with the study by Gonzalez luna et al. ${ }^{32}$ and this could be due to physical interaction of nanoparticles and the debris. More smear layer is removed when silver nanoparticle irrigant is used along with 17\% EDTA (Group B).

Sodium hypochlorite (Group C) has shown least smear layer removal ability as it is capable of removing only the organic portion of the smear layer.

Possible adverse effects associated with silver nanoparticle are discoloration of dentin and cytotoxicity. Gomes et al. evaluated the biocompatibility and disinfection ability of silver nanoparticle dispersion in comparison to $2.5 \%$ sodium hypochlorite. Result showed that silver nanoparticle dispersion was biocompatible and able to disinfect the infected dentin tubules, similar to $2.5 \% \mathrm{NaOCl}$. The toxic concentrations of silver ions are approximately $1-10 \mathrm{mg} / \mathrm{L}$, and silver nanoparticle are 10-100 mg/L for eukaryotic cells 11,40

From the results obtained from this study silver nanoparticle when used as a final irrigant against $E$. faecalis biofilm exhibited moderate bactericidal capacity compared to $5.25 \%$ sodium hypochlorite and better smear layer removal efficacy when combined along with 17\% EDTA. Therefore, silver nanoparticle solution along with $17 \%$ EDTA can be used as an alternative final irrigant. Main limitations of this study were only monospecies biofilm were assessed and only 3-day maturation of biofilm was considered. More future in vitro and in vivo studies on polymicrobial biofilm, antimicrobial efficacy of different nanoparticles, its modifications focusing on its size, concentration and form of delivery, efficacy in the presence of dentin, and other organic constituents within the canal has to be conducted to validate the results and get more conclusive evidence and possible commercial use in endodontics as an irrigant and medicament.

\section{Conclusion}

From the results obtained and within the limits of this in vitro study, it was observed that $5.25 \% \mathrm{NaOCl}$ has the highest antibacterial efficacy followed by AgNp irrigant, AgNp + 17\% EDTA as irrigant. The greatest smear layer removal efficacy was seen when AgNp + $17 \%$ EDTA and $5.25 \% \mathrm{NaOCl}+17 \%$ EDTA irrigant was used.

\section{References}

1. Zhao D, Shen Y, Peng B, et al. Root canal preparation of mandibular molars with 3 nickel-titanium rotary instruments: a micro-computed tomographic study. J Endod 2014;40(11):1860-1864. DOI: 10.1016/j. joen.2014.06.023

2. Haapasalo M, Endal U, Zandi H, et al. Eradication of endodontic infection by instrumentation and irrigation solutions. Endod Top 2005;10(1):77-102. DOI: 10.1111/j.1601-1546.2005.00135.x 
3. Gomes-Filho JE, Silva FO, Watanabe $\mathrm{S}$, et al. Tissue reaction to silver nanoparticles dispersion as an alternative irrigating solution. J Endod 2010;36(10):1698-1702. DOI: 10.1016/j.joen.2010.07.007

4. Stuart $\mathrm{CH}$, Schwartz SA, Beeson TJ, et al. Enterococcus faecalis: its role in root canal treatment failure and current concepts in retreatment. J Endod 2006;32(2):93-98. DOI: 10.1016/j.joen.2005.10.049

5. Saito K, Webb TD, Imamura GM, et al. Effect of shortened irrigation times with $17 \%$ ethylene diamine tetra-acetic acid on smear layer removal after rotary canal instrumentation. J Endod 2008;34:1011-1014. DOI: 10.1016/j.joen.2008.05.014

6. Rôças IN, Siqueira Jr JF, Santos KR. Association of Enterococcus faecalis with different forms of periradicular diseases. J Endod 2004; 30(5):315-320. DOI: 10.1097/00004770-200405000-00004

7. Evans M, Davies JK, Sundqvist G, et al. Mechanisms involved in the resistance of Enterococcus faecalis to calcium hydroxide. Int Endod J 2002;35(3):221-228. DOI: 10.1046/j.1365-2591.2002.00504.x

8. Distel JW, Hatton JF, Gillespie MJ. Biofilm formation in medicated root canals. J Endod 2002;28(10):689-693. DOI: 10.1097/00004770-200210000-00003

9. Senia ES, Marshall FJ, Rosen S. The solvent action of sodium hypochlorite on pulp tissue of extracted teeth. Oral Surg Oral Med Oral Pathol 1971;31(1):96-103. DOI: 10.1016/0030-4220(71)90040-5

10. Shrestha A, Kishen A. Antibacterial nanoparticles in endodontics: a review. JEndod 2016;42(10):1417-1426.DOI: 10.1016/j.joen.2016.05.021

11. Kishen A. Nanotechnology In Endodontics. Springer International $\mathrm{Pu} ; 2016$.

12. Ibrahim AIO, Moodley DS, Petrik L, et al. Use of antibacterial nanoparticles in Endodontics. South Afr Dent J 2017;72(3):105-112.

13. Rai MK, Deshmukh SD, Ingle AP, et al. Silver nanoparticles: the powerful nanoweapon against multidrug-resistant bacteria. J Appl Microbiol 2012;112(5):841-852. DOI: 10.1111/j.1365-2672.2012.05253.x

14. Kim JS, KukE, Yu KN, et al. Antimicrobial effects of silver nanoparticles Nanomedicine 2007;3(1):95-101. DOI: 10.1016/j.nano.2006.12.001

15. Torabinejad M, Khademi AA, Babagoli J, et al. A new solution for the removal of the smear layer J Endod 2003;29(3):170-175. DOI: $10.1097 / 00004770-200303000-00002$

16. Zoletti GO, Siqueira Jr JF, Santos KRN. Identification of Enterococcus faecalis in root-filled teeth with or without periradicular lesions by culture-dependent and-independent approaches. J Endod 2006; 32(8):722-726. DOI: 10.1016/j.joen.2006.02.001

17. Hancock III HH, Sigurdsson A, Trope M, et al. Bacteria isolated after unsuccessful endodontic treatment in a North American population. Oral Surg Oral Med Oral Pathol Oral Radiol Endod 2001;91(5):579-586. DOI: 10.1067/moe.2001.113587

18. Siqueira JF, Rôças IN, Ricucci D. Biofilms in endodontic infection. Endodontic Topics 2012;22(1):33-49. DOI: 10.1111/j.1601-1546. 2012.00279.x

19. Ingle Jl, Baumgartner JC. Ingle's endodontics. PMPH-USA; 2008.

20. Neelakantan $P$, Romero $M$, Vera J, et al. Biofilms in endodonticscurrent status and future directions. Int J Mol Sci 2017;18(8):174. DOI:10.3390/ijms18081748

21. Gomes B, Ferraz CCR, Vianna ME, et al. In vitro antimicrobial activity of several concentrations of sodium hypochlorite and chlorhexidine gluconate in the elimination of Enterococcus faecalis. Int Endod J 2001;34(6):424-428. DOI: 10.1046/j.1365-2591.2001.00410.x

22. Haapasalo HK, Sirén EK, Waltimo TMT, et al. Inactivation of local root canal medicaments by dentine: an in vitro study. Int Endod J 2000;33(2):126-131. DOI: 10.1046/j.1365-2591.2000.00291.x

23. Gomes BPFA, Souza SFC, Ferraz CCR, et al. Effectiveness of $2 \%$ chlorhexidine gel and calcium hydroxide against Enterococcus faecalis in bovine root dentine in vitro. Int Endod J 2003;36(4):267-275. DOI: 10.1046/j.1365-2591.2003.00634.x

24. Mohammadi Z, Shalavi S. Effect of hydroxyapatite and bovine serum albumin on the antibacterial activity of MTA. Iran Endod J 2011;6(4):136-139. PMID -23130067.

25. Rosen E, Tsesis I, Elbahary S, et al. Eradication of enterococcus faecalis biofilms on human dentin. Front Microbiol 2016;7:2055. DOI: 10.3389/fmicb.2016.02055

26. Lok C-N, Ho C-M, Chen R, et al. Silver nanoparticles: partial oxidation and antibacterial activities. JBIC J Biol Inorg Chem 2007;12(4):527-534. DOI: $10.1007 / \mathrm{s} 00775-007-0208-z$

27. Guzman M, Dille J, Godet S. Synthesis and antibacterial activity of silver nanoparticles against gram-positive and gram-negative bacteria. Nanomedicine 2012;8(1):37-45. DOI: 10.1016/j.nano. 2011.05.007

28. Morones JR, Elechiguerra JL, Camacho A, et al. The bactericidal effect of silver nanoparticles. Nanotechnology 2005;16(10):2346. DOI: 10.1088/0957-4484/16/10/059

29. Marambio-Jones C, Hoek EM. A review of the antibacterial effects of silver nanomaterials and potential implications for human health and the environment. J Nanoparticle Res 2010;12(5):1531-1551. DOI: 10.1007/s11051-010-9900-y

30. AshaRani PV, Low Kah Mun G, Hande MP, et al. Cytotoxicity and genotoxicity of silver nanoparticles in human cells. ACS Nano 2008;3(2):279-90. 10.1021/nn800596w

31. Zhuang $P, G a o Y$, Ling J, et al. Bactericidal effect of nano-silver against $E$. faecalis biofilm on dentin. Chin J Stomatol Res Electron Ed 2011;5:463-469.

32. González-Luna IV P, Martínez-Castañón G-A, Zavala-Alonso N-V, et al. Bactericide effect of silver nanoparticles as a final irrigation agent in endodontics on Enterococcus faecalis: an ex vivo study. J Nanomater 2016;2016. DOI: 10.1155/2016/7597295

33. Hou X, Fu H, Han Y, et al. Analysis of transcriptome in Enterococcus faecalis treated with silver nanoparticles. J Nanosci Nanotechnol 2020;20(2):1046-1055. DOI: 10.1166/jnn.2020.16940

34. Martinez-Andrade JM, Avalos-Borja M, Vilchis-Nestor AR, et al. Dual function of EDTA with silver nanoparticles for root canal treatment-A novel modification. PloS One 2018;13(1):e0190866. DOI: $10.1371 /$ journal.pone. 0190866

35. Rodrigues CT, de Andrade FB, de Vasconcelos L, et al. Antibacterial properties of silver nanoparticles as a root canal irrigant against Enterococcus faecalis biofilm and infected dentinal tubules. Int Endod J 2018; 51(8):901-911. DOI: 10.1111/iej.12904

36. Balto H, Bukhary S, Al-Omran O, et al. Combined effect of a mixture of silver nanoparticles and calcium hydroxide against Enterococcus faecalis biofilm. J Endod 2020; 46(11):1689-1694. DOI: 10.1016/j. joen.2020.07.001

37. Wu D, Fan W, Kishen A, et al. Evaluation of the antibacterial efficacy of silver nanoparticles against Enterococcus faecalis biofilm. J Endod 2014;40(2):285-290. DOI: 10.1016/j.joen.2013.08.022

38. Kishen A, Shi Z, Shrestha A, et al. An investigation on the antibacterial and antibiofilm efficacy of cationic nanoparticulates for root canal disinfection J Endod 2008;34(12):1515-1520. DOI: 10.1016/j. joen.2008.08.035

39. Shrestha A, Zhilong S, Gee NK, et al. Nanoparticulates for antibiofilm treatment and effect of aging on its antibacterial activity. J Endod 2010;36(6):1030-1035. DOI: 10.1016/j.joen.2010.02.008

40. Gomes-FilHo JE, Silva FO, Watanabe S, et al. Evaluation of silver nanoparticles as irrigating solution. Dent Press Endod 2013;3(2):16-23. 